\title{
17p13.3 quadruplication: a prenatal and postpartum clinical characterization of a copy number variant
}

\author{
Nicholas Farris, ${ }^{1}$ Helena $\mathrm{Wu}^{2}{ }^{2}$ Sara Said-Delgado, ${ }^{3}$ Barrie Suskin, ${ }^{4}$ \\ and Susan Klugman ${ }^{4}$ \\ ${ }^{1}$ Children's Hospital Medical Center of Akron, Ohio 44308, USA; ${ }^{2}$ Albert Einstein College of Medicine, Bronx, \\ New York 10461, USA; ${ }^{3}$ Department of Obstetrics and Gynecology, Bronx Lebanon Hospital, Bronx, New York \\ 10457, USA; ${ }^{4}$ Division of Reproductive and Medical Genetics, Department of Obstetrics and Gynecology \\ and Women's Health, Albert Einstein College of Medicine/Montefiore Medical Center, Bronx, New York \\ 10461, USA
}

Corresponding author: NFarris@ akronchildrens.org

(C) 2018 Farris et al. This article is distributed under the terms of the Creative Commons Attribution-NonCommercial License, which permits reuse and redistribution, except for commercial purposes, provided that the original author and source are credited.

Ontology terms: aplasia/ hypoplasia of the corpus callosum; congenital microcephaly; facial hypotonia; mild fetal ventriculomegaly; severe global developmental delay

Published by Cold Spring Harbor Laboratory Press

doi: 10.1101/mcs.a002196
Abstract Prenatal genetic testing has advanced rapidly in the past decade. However, not all results, including variants, are well understood. We report the finding of a $2.5-\mathrm{Mb}$ gene region quadruplication of Chromosome 17p13.3. This region is well characterized for the deletion leading to Miller-Dieker syndrome but has an unclear replication phenotype. Invasive testing performed after ultrasound abnormalities were seen revealed the quadruplication sequence as well as a short segment $(850 \mathrm{~kb})$ with $\times 5$ copy number variation. This region has previously been reported in a collection of duplications with shared phenotype; our quadruplication suggests similarities in phenotype. This raises the hypothesis of a potential spectrum or copy number variant-based phenotype.

\section{INTRODUCTION}

Anomalies seen on ultrasound are a common reason for prenatal invasive testing. Many of the chromosomal abnormalities found will be seen on karyotype; however, others will only be discovered via microarray. The extra yield from microarray over karyotype is at least $6 \%$ (Wapner et al. 2012) and is as high as 13\% when more than one organ system is involved (Donnelly et al. 2014). Copy number variants are often deletions or duplications but can be triplications and, even more rarely, quadruplications.

This case describes an anomaly of the 17p13.3 region, which includes the two most notable genes of YWHAE (encoding for signal transduction proteins) and PAFAH1B1 (homolog of Drosophila gene LIS1 necessary for GTPase actin functioning and cytoskeletal formation). The region is most widely known for the deletion associated with Miller-Dieker syndrome (Miller 1963; H. Dieker et al. 1969; Dobyns et al. 1983). Miller-Dieker syndrome is a multisystem genetic deletion syndrome with both organ abnormalities and phenotypic dimorphisms. Some notable abnormalities include the following: microcephaly, cerebral agyria/ pachygyria, lissencephaly, ventriculomegaly, agenesis/dysgenesis of the corpus collosum, and seizures. Other organ dysfunctions have included cardiac defects, genitourinary defects 
(hypoplasia), and omphaloceles. Facial findings include prominent forehead and occiput, bitemporal narrowing, furrowed brow, small anteverted nostrils, low-set ears, prominent lip, and micrognathia. Physical and cognitive development are both affected including IUGR and intellectual delays (Chen et al. 2013).

Duplications of 17p13.3 have also been reported (Capra et al. 2012; Curry et al. 2013). The duplication is far more rare than the deletion syndrome so commonalities are less well identified, but shared abnormalities seem to include abnormal brain development and dysmorphic facial features. In this case we present a quadruplication of this region.

\section{RESULTS}

\section{Clinical Presentation and Family History}

A 27-yr-old G5P2022 Hispanic woman with no significant past medical or obstetrical history was referred at 22 weeks to our reproductive genetics clinic after an anatomical survey showed ascites, echogenic bowel, mild pyelectasis, and borderline ventriculomegaly.

The proband's family history includes a maternal grandmother, great grandmother, great uncle, and aunt with intellectual disabilities, an aunt with schizophrenia, a sister with attention deficit hyperactive disorder, and a cousin with autism. Paternal family history was unavailable.

The differential diagnosis for the above anomalies was discussed with the patient and included chromosomal anomalies, genetic syndromes, and maternal peripartum infection. Initial laboratory findings included an elevated cytomegalovirus (CMV) IgM and lgG. Follow-up CMV avidity testing was high, indicating a low suspicion for recent infection. At the time, the patient refused amniocentesis because of the risk of pregnancy loss.

During the pregnancy, the mother was followed closely for infection and the fetus was closely monitored with repeat sonograms. Mild pyelectasis increased to moderate hydronephrosis from the second to the third trimester (Fig. 1C; 13.5 and $15.5 \mathrm{~mm}$, respectively, increased from $4 \mathrm{~mm}$ at initial visit). Ascites remained stable (Fig. 1A). Echogenic bowel remained prominent (Fig. 1B). Cardiac assessment showed mild enlargement of the left atrium and mild tricuspid regurgitation without other signs of cardiac dysfunction. There was bilateral ventriculomegaly $(20$ and $12 \mathrm{~mm})$ and enlargement of the third ventricle. Growth remained appropriate for gestational age. The patient opted for amniocentesis at 35 wk for delivery planning.

The patient underwent a repeat cesarean section and delivered a full-term, $7 \mathrm{lb}, 7 \mathrm{oz}$ female, Apgars 7 at $1 \mathrm{~min}$ and 8 at $5 \mathrm{~min}$, who was transferred to the NICU for further evaluation and observation.

A

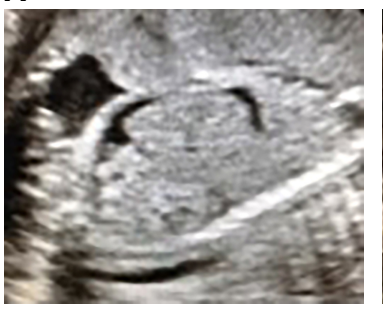

B

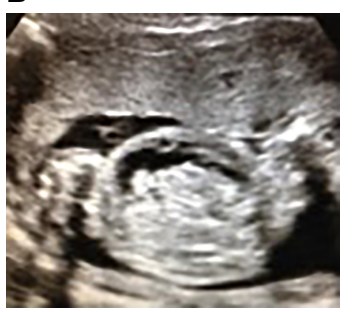

C

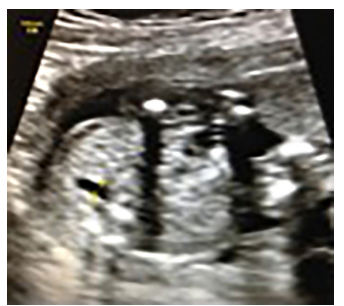

Figure 1. Ultrasound at 22 weeks demonstrated multiple abnormalities. $(A)$ abdominal ascites, $(B)$ echogenic bowel, and $(C)$ pyelectasis. 
A

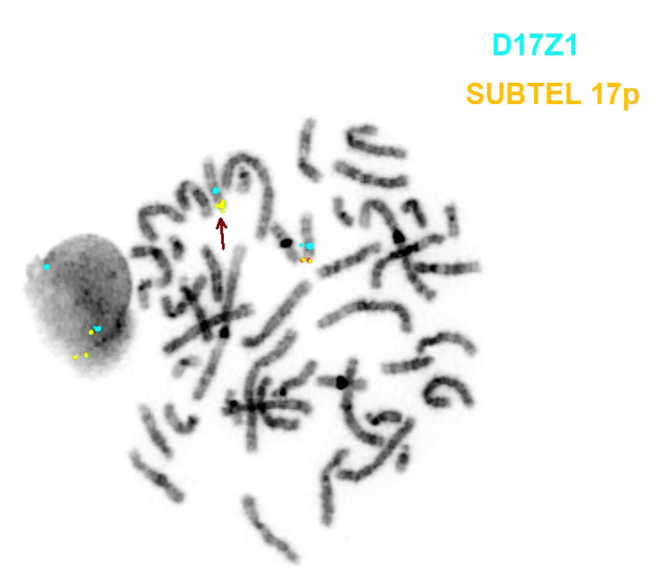

B

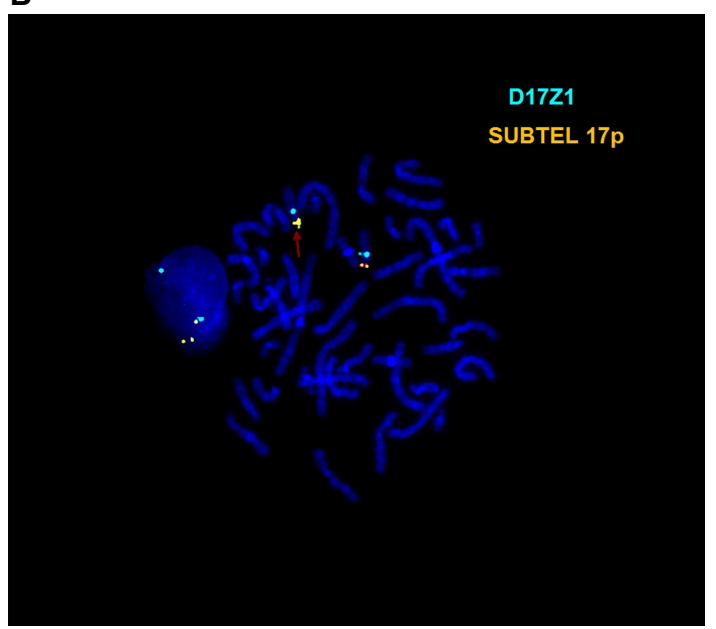

Figure 2. FISH analysis with increased signal at Chromosome 17p.

\section{Genomic Analysis}

Amniocentesis using fluorescent in situ hybridization (FISH) and karyotype suggested an increased dosage of region 17p as well as a mosaic Turner syndrome (12 of 68 cells had single $X$ chromosomes). The oligo-SNP array demonstrated a 2.5-Mb copy gain with value of 4 and an embedded 850-kb segment with a copy gain value of 5 in the 17p13.3 region. The lab reported a fetal 17p13.3 abnormality (CGP13-50811 arr[hg19], 17p13.3(525-2,534,891)x4-5 on prenatal sample, and postnatal confirmation reported a similar genome location of 17p13.3(525-2,529,405)x4-5 (Fig. 2).

Using the UCSC genome browser, we were able to compare our chromosome quadruplication region to those previously reported (Kent et al. 2002). Our quadruplication region included the YWHAE, BHLHA9, and HIC1 genes; the PAFAH1BI (LIS1 analog) is partially included based on both prenatal and postnatal samples. The further analysis of CMV by PCR was negative at this time, which was expected because of the length of time since the primary infection. Chromosomal analysis by Oligo-SNP analysis for mother showed $46 X X$ with no regions of increased signal $(\operatorname{arr}(1-22, X) \times 2$ normal female)); there was no available paternal genetic testing (Table 1).

\section{Phenotypic Analysis}

At birth, the infant was in the 50th percentile for height, 25th percentile for weight, and 10th percentile for head circumference. Postnatal testing was performed by Quest Diagnostics, and karyotype examination confirmed mosaic Turner $45, \mathrm{X}$, reported as six of 80 cells analyzed with $45, X$ pairings. Microarray confirmed a chromosomal abnormality of $17 \mathrm{p} 13.3$. Next-generation sequencing was not performed. An MRI of the brain demonstrated marked hypoplasia-partial agenesis of the corpus callosum without acute intracranial lesion or hemorrhage. Renal ultrasound showed moderate bilateral hydronephrosis without cystic or solid masses. Retrograde voiding cystourethrogram (VCUG) found grade 3 right vesicoureteral reflux. Echocardiogram showed a small atrial septal defect.

Physical examination demonstrated dysmorphic features including low-set ears with normal architecture and high arched palate. At a neurology evaluation at 4 months old, the infant could bring hands together, reach, had some head control, and had begun to make cooing noises. At 6 months old, the infant was able to smile when stimulated and was 


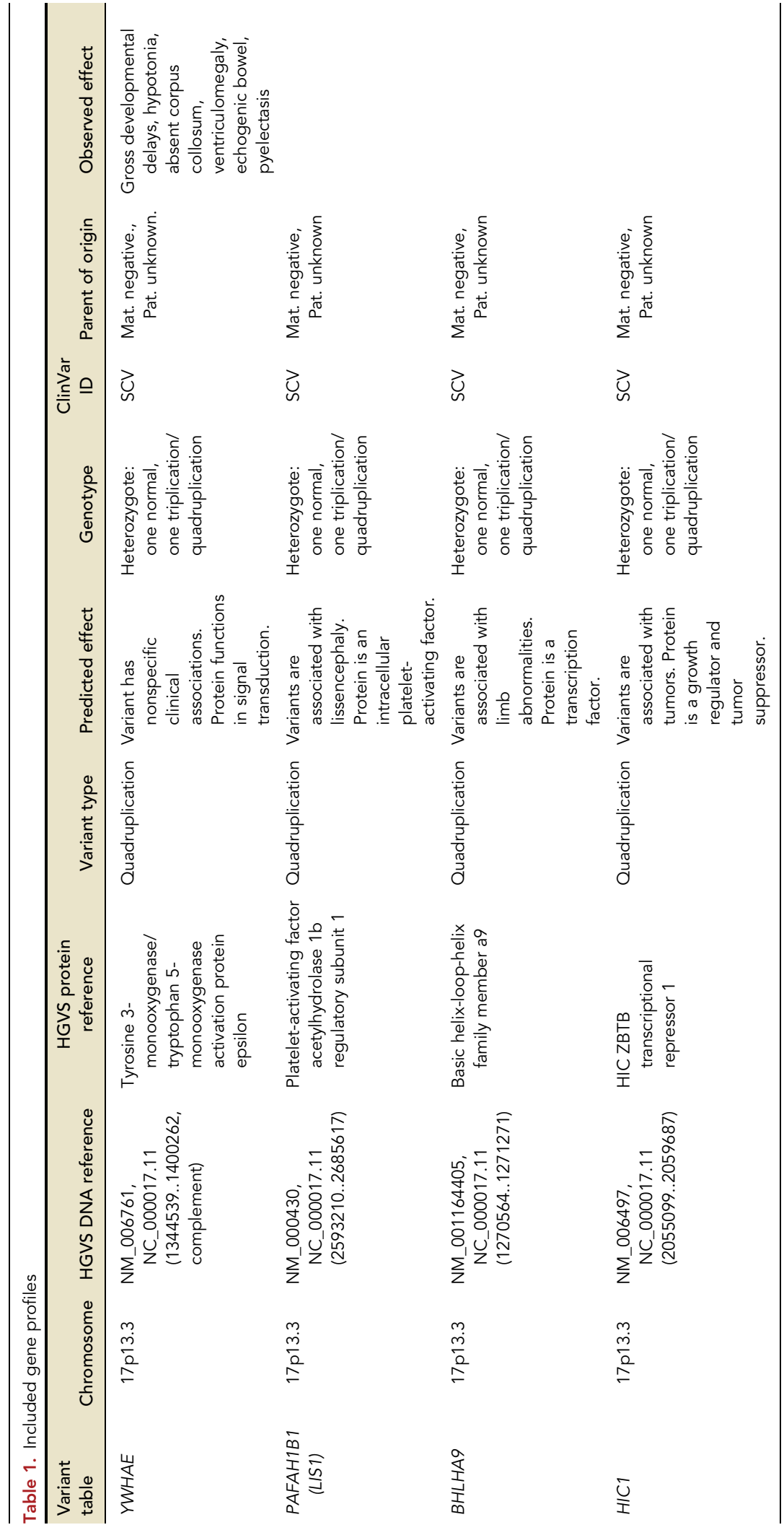


able to hold objects but could not transfer and mild hypotonia was noted. At 18 months old, physical exam demonstrated microcephaly (between the 2nd and 5th percentile). Developmental assessment demonstrated an infant with global developmental delay. Motor delays include rolling over at 11 months and difficulty sitting unsupported at 18 months old. The infant verbalized unformed words only and demonstrated an immature pincer grasp. At 18 months old, the child demonstrated development consistent with that of a 5-mo-old.

\section{DISCUSSION}

With the widespread use of prenatal microarray, it is inevitable that physicians will encounter situations of variants of uncertain significance or VOUS. Some pediatric deletions and duplications have been well described allowing more precise prognoses. However, for those that have not been well described, it is very challenging to predict pediatric phenotype from the prenatal genotype. This makes counseling expectant mothers with uncertain genetic diagnoses that much more complicated. In our case, the patient was committed to the pregnancy and only agreed to amniocentesis late in gestation. Given the unknown clinical phenotype or expected outcome after delivery, having this genetic variant during the second trimester would have made counseling the mother on continuing versus terminating the pregnancy difficult.

The region noted in our case, 17p13.3, is best known for a deletion with the associated syndrome, Miller-Dieker (Curry et al. 2013). This syndrome has associated lissencephaly due to aberrant neuron migration. Sequencing of this region identifies the two genes of most importance-YWHAE (encoding for signal transduction proteins) and PAFAH1B1 (homolog of Drosophila gene LIS1 necessary for GTPase actin functioning and cytoskeletal formation) (Lo Nigro et al. 1997; Luk et al. 1997). Initial human studies suggested a potential dose-dependent phenotype with imaging results and cognitive functioning (Bi et al. 2009).

Curry et al. (2013) published a study of this location as a site of duplication with heterogeneous breakpoints and a number of different size mutations. The phenotype is variable and includes three categories: cleft lip and palate (CLP), split-hand/food malformation with long-bone deficiency (SHFLD), and marfanoid habitus. The variable presentation is likely due to nonuniform mutation sequences. Commonalities in these patients included neurodevelopmental disorders (developmental delay/intellectual disability/autism spectrum disorder), hypotonia (generalized and notable particularly in the face), and shared imaging deficits (particularly in the corpus collosum) (Curry et al. 2013).

This proband child shares clinical phenotypes as those described by Curry et al. Her prenatal ultrasound shared some commonalities with those findings reported in individual patients from Curry et al. (2013) including dilated renal pelvises, agenesis of corpus collosum (confirmed on MRI), and ventriculomegaly. Her facies show a similar hypoplasia, elongated facies, and small mouth similar to all eight of the individuals reported by Curry et al. who were photographed; see Figure 3. These features just described were not subcategorized to a specific phenotype. From her pediatric well visits, she demonstrates gross developmental delays. Because of the patient's age, many of the abnormalities in childhood and development (i.e., autism spectrum disorder) cannot be commented on.

The microarray analysis for our patient demonstrated a 2.5-Mb quadruplication region including all four of the notable genes reported by Curry et al.: YWHAE, BHLHA9, and HIC1 genes with partial involvement of PAFAH1BI (LIS1 analog). This quadruplicated region is similar to the duplication seen in nine of the 34 patients reported by Curry et al. who have mutations of all four genes. 


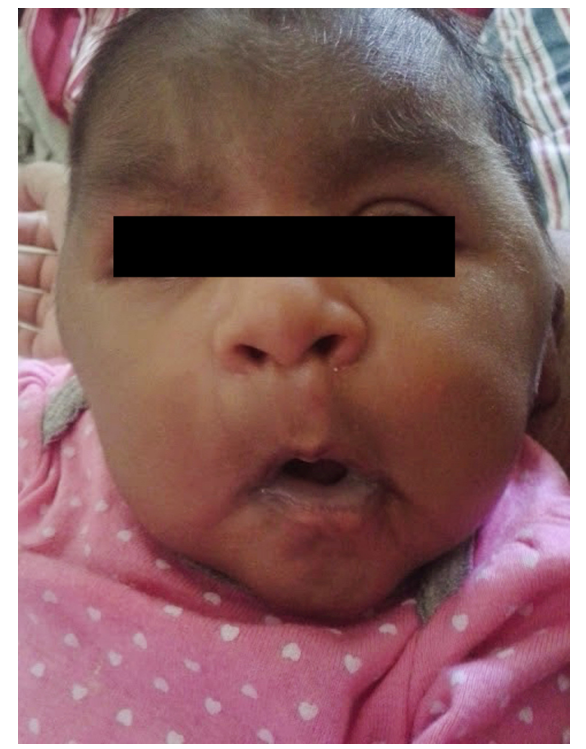

Figure 3. Photo of the proband at $\sim 10$ months of age. The face shows evidence of elongation and generalized hypotonia.

See Table 2 for some generalized comparison of the three genetic abnormalities (Genetics Home Reference 2017).

It is also important to discuss the concurrent diagnosis of mosaic Turner syndrome. Because of the partial abnormality, no clear phenotype would be identifiable. One expected physical abnormality that may impact on this patient is the short stature: Whereas physical development is delayed in the 17p13.3 duplication syndrome, delays for this child could also be due to the mosaic Turner syndrome. Additionally, cardiac and renal abnormalities are sometimes present in Turner syndrome, a similar abnormality described in the 17p13.3

Table 2. Comparative patient characteristics by genomic abnormality

\begin{tabular}{|c|c|c|c|}
\hline & Miller-Dieker & 17p13.3 duplication & Proband quadruplication \\
\hline \multicolumn{4}{|l|}{ Central nervous system } \\
\hline Lissencephaly & Yes & Absent & Absent \\
\hline Cerebral cortical atrophy & Yes & Absent & Absent \\
\hline $\begin{array}{l}\text { Partial development or agenesis of } \\
\text { corpus collosum }\end{array}$ & Absent & Variable (6/19 Imaged) & Yes \\
\hline Posterior fossa abnormalities & Absent & Variable (9/19 Imaged) & Absent \\
\hline Cerebellar vermis hypoplasia & Absent & Variable (8/19 imaged) & Absent \\
\hline Seizures & Yes & Absent & Absent \\
\hline \multicolumn{4}{|l|}{ Facial dismorphisms } \\
\hline Hypotonia & Yes & Yes & Yes \\
\hline Elongated facies & & Yes & Yes \\
\hline Cleft lip/palate & Yes & Variable & Absent \\
\hline \multicolumn{4}{|l|}{ Developmental } \\
\hline Gross developmental delay & Yes & Yes & Yes \\
\hline Generalized hypotonia & Yes & Yes & Yes \\
\hline Intellectual delay & Yes & Yes & Yes \\
\hline
\end{tabular}


duplication. Other more often shared genetic abnormalities are likely to be common in these two syndromes. However, given the gross developmental delay noted at the follow-up pediatric visits, this child likely shows consequences of the quadruplication based on the fact that the majority of Turner syndrome patients have normal neurologic and cognitive development.

To our knowledge, a quadruplication of this region has not been previously reported. It is possible that this region is subject to variable copy number gain. Clinical presentation likely shares similarities, although not specific, to the duplication mutation (by abnormal facies, hypotonia, and global development delay), but could show increased severity because of the increased quantity of genetic information.

It is notable that if the patient underwent cell-free DNA testing or noninvasive prenatal screening (NIPS) the result would be low risk. This is not surprising in that the duplication does not involve the traditionally screened chromosomes $(13,18,21, X$, and $Y)$. In the future, it may be possible to screen for broader array of microdeletions and microduplications via cell-free fetal DNA. At this time, it is important to remind patients of the availability of microarray analysis with invasive prenatal testing, especially in those cases with ultrasound anomalies.

\section{METHODS}

Testing was done by Quest Diagnostics using Affymetric CytoScan HD assay Oligo-SNP array as follows: 2.67 million probes, 1.9 million copy number probes, and 750 thousand SNP probes; interprobe distance is 1150 base pairs; the thresholds of $>200 \mathrm{~kb}$ for copy gains, $>50 \mathrm{~kb}$ for losses, and $10 \mathrm{Mb}$ for segments of homozygosity.

\section{ADDITIONAL INFORMATION}

\section{Data Deposition and Access}

The variant has been submitted to ClinVar (https://www.ncbi.nlm.nih.gov/clinvar/) and can be found under accession number SCV000747897.

\section{Ethics Statement}

Informed consent for publication, including deposition to public repository, was obtained from the patient. IRB approval was not required by the parent institution in order to publish a case report.

\section{Acknowledgments}

We would like to acknowledge Loretta Mahon of Quest Laboratories.

Competing Interest Statement

The authors have declared no competing interest.

Received June 19, 2017; accepted in revised form March 30, 2018.

\section{Author Contributions}

N.F. was the primary author of this paper, S.K. served as the senior advisor, S.S.-D. provided significant contributions to data collection and management, and H.W. and B.S. also provided material contribution and editing input.

\section{Funding}

There is no funding to report for this submission. 


\section{REFERENCES}

Bi W, Sapir T, Shchelochkov OA, Zhang F, Withers MA, Hunter JV, Levy T, Shinder V, Peiffer DA, Gunderson KL, et al. 2009. Increased LIS1 expression affects human and mouse brain development. Nat Genet 41: $168-177$.

Capra V, Mirabelli-Badenier M, Stagnaro M, Rossi A, Tassano E, Gimelli S, Gimelli G. 2012. Identification of a rare 17p13.3 duplication including the BHLHA9 and YWHAE genes in a family with developmental delay and behavioural problems. BMC Med Genet 13: 93.

Chen CP, Chang TY, Guo WY, Wu PC, Wang LK, Chern SR, Wu PS, Su JW, Chen YT, Chen LF, et al. 2013. Chromosome 17p13.3 deletion syndrome: aCGH characterization, prenatal findings and diagnosis, and literature review. Gene 532: 152-159.

Curry CJ, Rosenfeld JA, Grant E, Gripp KW, Anderson C, Aylsworth AS, Saad TB, Chizhikov VV, Dybose G, Fagerberg C. 2013. The duplication 17p13.3 phenotype: analysis of 21 families delineates developmental, behavioral and brain abnormalities, and rare variant phenotypes. Am J Med Genet A 161A: 1833-1852.

Dieker RH, Edwards RH, ZuRhein G, Chou SM, Hartman HA, Opitz JM. 1969. The lissencephaly syndrome. In The clinical delineation of birth defects: malformation syndromes (ed. Bergsma D), pp. 53-64. National Foundation-March of Dimes II, New York.

Dobyns WB, Stratton RF, Parke JT, Greenberg F, Nussbaum RL, Ledbetter DH. 1983. Miller-Dieker syndrome: lissencephaly and monosomy 17p. J Pediatr 102: 552-558.

Donnelly JC, Platt LD, Rebarber A, Zachary J, Grobman WA, Wapner RJ. 2014. Association of copy number variants with specific ultrasonographically detected fetal anomalies. Obstet Gynecol 124: 83-90.

Genetics Home Reference, N.I.o.H. (2017, November 2009). https://ghr.nlm.nih.gov/condition/Miller-Diekersyndrome\#sourcesforpage. Retrieved August 31, 2017.

Kent WJ, Sugnet CW, Furey TS, Roskin KM, Pringle TH, Zahler AM, Haussler D. 2002. The human genome browser at UCSC. Genome Res 12: 996-1006.

Lo Nigro C, Chong CS, Smith AC, Dobyns WB, Carrozzo R, Ledbetter DH. 1997. Point mutations and an intragenic deletion in LIS1, the lissencephaly causative gene in isolated lissencephaly sequence and Miller-Dieker syndrome. Hum Mol Genet 6: 157-164.

Luk SC, Garcia-Barcelo M, Tsui SK, Fung KP, Lee CY, Waye MM. 1997. Assignment of the human 14-3-3 epsilon isoform (YWHAE) to human Chromosome 17p13 by in situ hybridization. Cytogenet Cell Genet 78: 105-106.

Miller JQ. 1963. Lissencephaly in 2 siblings. Neurology 13: 841-850.

Wapner RJ, Martin CL, Levy B, Ballif BC, Eng CM, Zachary JM, Savage M, Platt LD, Saltzman D, Grobman WA, et al. 2012. Chromosomal microarray versus karyotyping for prenatal diagnosis. N Engl J Med 367: 2175-2184. 


\section{COLD SPRING HARBOR Molecular Case Studies}

\section{7p13.3 quadruplication: a prenatal and postpartum clinical characterization of a copy number variant}

Nicholas Farris, Helena Wu, Sara Said-Delgado, et al.

Cold Spring Harb Mol Case Stud 2018, 4: a002196

Access the most recent version at doi: $10.1101 / \mathrm{mcs} . a 002196$

References This article cites 11 articles, 1 of which can be accessed free at: http://molecularcasestudies.cshlp.org/content/4/3/a002196.full.html\#ref-list-1

License This article is distributed under the terms of the Creative Commons Attribution-NonCommercial License, which permits reuse and redistribution, except for commercial purposes, provided that the original author and source are credited.

Email Alerting Receive free email alerts when new articles cite this article - sign up in the box at the Service top right corner of the article or click here. 